\title{
Health technology assessment of treatment for peripheral arterial disease
}

Citation for published version (APA):

Petersohn, S. (2021). Health technology assessment of treatment for peripheral arterial disease. [Doctoral Thesis, Maastricht University]. Maastricht University. https://doi.org/10.26481/dis.20210114sp

Document status and date:

Published: 01/01/2021

DOI:

10.26481/dis.20210114sp

Document Version:

Publisher's PDF, also known as Version of record

\section{Please check the document version of this publication:}

- A submitted manuscript is the version of the article upon submission and before peer-review. There can be important differences between the submitted version and the official published version of record.

People interested in the research are advised to contact the author for the final version of the publication, or visit the DOI to the publisher's website.

- The final author version and the galley proof are versions of the publication after peer review.

- The final published version features the final layout of the paper including the volume, issue and page numbers.

Link to publication

\footnotetext{
General rights rights.

- You may freely distribute the URL identifying the publication in the public portal. please follow below link for the End User Agreement:

www.umlib.nl/taverne-license

Take down policy

If you believe that this document breaches copyright please contact us at:

repository@maastrichtuniversity.nl

providing details and we will investigate your claim.
}

Copyright and moral rights for the publications made accessible in the public portal are retained by the authors and/or other copyright owners and it is a condition of accessing publications that users recognise and abide by the legal requirements associated with these

- Users may download and print one copy of any publication from the public portal for the purpose of private study or research.

- You may not further distribute the material or use it for any profit-making activity or commercial gain

If the publication is distributed under the terms of Article $25 \mathrm{fa}$ of the Dutch Copyright Act, indicated by the "Taverne" license above, 


\section{SUMMARY}


PAD is a widespread cardiovascular disease, in 2010 an estimated 40.5 million people lived with PAD in the European region (1), and patient numbers are increasing worldwide (2). Some patients with PAD experience chronic pain, have a reduced walking distance or may become dependent on other people to handle everyday life (3). Additionally, patients with PAD have a high risk for cardiovascular events such as heart attack or stroke, and for death from cardiovascular causes. Treatment of PAD therefore includes physiotherapy, lifestyle interventions, treatment with drugs i.e. pharmacological treatment, and (repeated) invasive treatment, this can include surgery or minimally-invasive interventions to improve the blood flow to the affected extremities $(2,4,5)$. New pharmacological treatment options and invasive treatment techniques and materials are becoming available, potentially reducing the burden of the disease to the patient, but also potentially increasing treatment costs and economic burden of PAD (6-17). In this context, the evaluation of costs, clinical outcomes, and the value for money i.e. cost-effectiveness of such new PAD treatments becomes increasingly relevant.

The objective of the thesis was to 1 ) investigate current PAD treatment patterns, 2) measure the quality of life of patients with PAD and to estimate the costs of PAD treatment, and 3 ) to assess the cost-effectiveness of new pharmacologic treatment strategies for PAD.

The first sub-objective aimed to identify groups of PAD patients with different treatment needs according to their cardiovascular risk and their probability of undergoing invasive PAD treatment, i.e. revascularization probability. Purpose of the identification of these groups was to explore if patient characteristics available at PAD diagnosis could be used to anticipate these treatment needs. Chapter 2, addressing this first sub-objective, described the analysis of characteristics of 274 patients newly diagnosed with PAD, and their treatment following diagnosis. Groups of PAD patients who developed different treatment needs were identified, and the relationship between group membership and patient characteristics were explored. This relationship was analysed in two ways: 1) Venn diagrams identified combinations of characteristics that were related to increased cardiovascular risk and reduced revascularization eligibility, 2) a regression analysis was used to analyse predictors of increased revascularization probability. On the one hand, the Venn diagrams identified four combinations of characteristics that characterized patients with reduced revascularization eligibility due their cardiovascular profile. These combinations were (a) insulin-dependent diabetes and impaired renal function, (b) History of $\mathrm{MI}$ and obesity, (c) insulin-dependent diabetes and history of MI, and (4) Age > 75, obesity and insulin-dependent diabetes. Within the patient cohort analysed, $5.1 \%$ of patients had such a combination of characteristics that identified them as likely ineligible for revascularization and thus dependent on stringent pharmacological cardiovascular prevention. Treatment for such patients who are at increased cardiovascular risk and need for extra measures to prevent PAD progression as well as cardiovascular events may 
benefit from intensified and individualised pharmacological treatment. On the other hand, the regression analysis showed a number of characteristics of patients who are at higher risk of undergoing invasive PAD treatment. These characteristics were younger age, lower physical functioning, and lower quality of life, as well as more severe Fontaine stages and worsening complaints. Identifying this group of patients who are more likely to need revascularization may help GPs treating PAD patients refer patients with such characteristics and signs of worsening of the disease to the vascular surgeon earlier. By involving the vascular surgeon earlier, the decision to switch from conservative to invasive treatment will not be delayed, which may benefit the patient. The findings of the study presented in Chapter 2 may help develop guidance for PAD treatment in the primary care setting, where additional information on a patient's future treatment needs may help doctors determine the best treatment approach for newly diagnosed PAD patients.

The second sub-objective of the thesis was to measure the quality of life of patients with PAD and to estimate the costs of PAD treatment in the first two years after diagnosis. Chapter 3 describes the quality of life of patients with new PAD, and the effect of invasive and conservative treatment using two different measurement instruments, the SF-6D and EQ-5D. Quality of life data from 229 patients with newly diagnosed PAD was analysed. The data had been collected during a time period of two years starting from diagnosis of PAD. The analyses compared the effect of non-invasive, i.e. conservative vs. invasive PAD treatment one and two years after diagnosis. To enable a comparison between the conservative and invasive treatment groups, differences in characteristics of the groups were adjusted for using a matching technique (propensity score matching). The effects of invasive treatment and conservative treatment were estimated, patient characteristics that influenced the extend of the treatment effect were identified. At year one, $30.6 \%$ of patients had received invasive treatment, $7.4 \%$ received invasive treatment during the second year. The EQ-5D instrument indicated that QoL after invasive treatment was higher, and more patients reported 'no problems' with pain/discomfort, mobility and usual activities after invasive treatment. The SF-6D instrument indicated that physical functioning, role limitations physical and pain were improved after invasive treatment. Both treatments showed a positive effect on quality of life measured by the EQ-5D, the SF$6 \mathrm{D}$ measured a small negative effect of conservative treatment. The comparison between patients who received invasive treatment and patients who received conservative treatment showed that the effect of treatment on quality of life was dependent on the quality of life at PAD diagnosis. Patients with lower quality of life and patients who experienced rest-pain at diagnosis gained more quality of life with PAD treatment. The difference in effect between conservative and invasive treatment was not statistically significant. The effect of invasive treatment was numerically larger. The analysis highlighted that both conservative and invasive treatment improved the quality of life of 
patients with PAD. The EQ-5D was more sensitive to changes in quality of life and differences between patient groups.

In Chapter 4 we quantified the costs of PAD and PAD treatment by estimating the costs of mild $P A D$ and moderate $P A D$, of peripheral revascularization i.e. invasive treatment and the cost of illness of PAD in the Netherlands overall (Chapter 4). Based on a bottom-up approach, using data from a smaller cohort of patients with PAD to estimate the costs within a much larger population, we estimated the cost of illness of PAD of the entire population of PAD patients in the Netherlands. Resource use and costs of 245 new Dutch PAD patients over a period of two years starting from PAD diagnosis were analysed. The impact of patient characteristics on PAD costs was explored using generalized linear regression. The costs of all new and all prevalent cases of PAD in the Netherlands were estimated. Over the first two years of treatment, $64.5 \%$ of patients exclusively received conservative treatment and $35.5 \%$ received invasive treatment at least once. Patients reported going to the GP and to the physiotherapist most often. The costs of PAD treatment were highest 3 months after diagnosis, and lowest 24 months after diagnosis. This was largely driven by the costs of invasive treatment. During the three months before PAD diagnosis, the majority of costs were related to specialist care. The total cost over the 27 months period ( 3 months before hospital-based diagnosis up to the 24 months after diagnosis) were $€ 7,504$ per patient; $€ 4,265$ ( $\mathrm{BCl} € 3,836$ - €4,796) in the first year and $€ 2,789(\mathrm{BCl} € 2,307-€ 3,324)$ in the second year. Costs were higher in patients with a high $\mathrm{BMI}$ and patients undergoing (repeated) invasive treatment, and lower in patients using cholesterol-lowering drugs and in patients with a high quality of life at diagnosis. The annual healthcare costs of patients with mild PAD and moderate PAD were $€ 2,031$ and $€ 2,318$, respectively. The costs of a revascularization were $€ 4,422$. Considering there are 26,489 new PAD patients in the Netherlands per year, the costs of new PAD are estimated to be $€ 113.1$ million in the first year and $€ 72.4$ million in the second year of PAD treatment (18). The annual costs of 613,000 prevalent PAD cases amount to $€ 1.26$ billion (19). This is comparable to the estimated $€ 1.3$ billion spent on the treatment of other cardiovascular disease such as ischemic heart disease in the Netherlands according to the European cardiovascular disease statistics (19).

The third and last sub-objective was to assess the cost-effectiveness of a new pharmacological treatment, rivaroxaban plus aspirin, for cardiovascular disease including PAD. In Chapter 5 we used a health-economic model to assess the costs and clinical outcomes of dual pathway inhibition (DPI) with $2.5 \mathrm{mg}$ rivaroxaban twice daily plus $100 \mathrm{mg}$ aspirin compared to aspirin alone for the prevention of heart attacks, strokes and death from cardiovascular disease in patients with coronary artery disease (CAD) or/and PAD. In patients with PAD, treatment with DPI and with aspirin were also compared to treatment with clopidogrel. A state transition model was developed, i.e. a model that simulated how a hypothetical cohort of patients treated with either of the treatment options would over 
time transition through a set of health states representing the different health conditions the patients could be in. In this case, these health conditions reflected stable disease, cardiovascular events as heart attack, or ischemic and haemorrhagic stroke, worsening of PAD, bleeding events, and death. To estimate the health outcomes and costs of each treatment option, costs and quality of life consequences were attached to each health state and summed up considering the amount of time patients would spend in each health state. Evidence from two clinical trials were used to model the effect of treatment with DPI, aspirin and clopidogrel. The model evaluated the treatments by estimating health outcomes and costs over a lifetime horizon. The results were standardized units of health gained, which was expressed in quality-adjusted life years (QALY), and costs. The cost per QALY was compared against the willingness-to-pay threshold per unit of health gained by the Dutch health authorities ( $€ 50,000$ per QALY). This reflected the value for money provided by the treatments from a Dutch healthcare perspective. The analysis showed that in CAD patients and in PAD patients, DPI provided the best health outcomes (longer survival, higher number of QALYs) and the highest costs. The additional costs stemmed largely from higher drug costs. This resulted in a cost per QALY of $€ 32,109$ for the treatment of CAD, and of $€ 26,381$ for the treatment of PAD when comparing DPI to aspirin. Treatment with clopidogrel was less cost-effective than with DPI. The probability of DPI being cost-effective was $92 \%$ and $56 \%$ in CAD and PAD patients. The annual healthcare costs would increase by $€ 38.7$ million if DPI was implemented for the treatment of CAD and would increase by $€ 29.0$ million if DPI was implemented for the treatment of PAD. The relationship between costs and effects of treatment with DPI differed in some subgroups of CAD and PAD patients. The costs per QALY was lowest in PAD patients with additional diseases and in CAD patients younger than 65 , this indicated that treatment would be most cost-effective in these patients. The costs per QALY were highest in PAD patients with carotid artery disease and in CAD patients older than 75 , this indicated that treatment with DPI would be less cost-effective. Chapter 5 ended with a discussion of limitations of the study and of the evidence used, and how these impact the decision uncertainty. It was highlighted that unavailability of detailed trial data contributed considerable uncertainty as assumptions had to be made where data from clinical trials should ideally be used, but these were not made available. The level of evidence informing the effectiveness of clopidogrel was identified as another uncertainty, specifically regarding the cost-effectiveness of DPI for the treatment of patients with PAD.

Chapter 6 continued by exploring the feasibility of a comprehensive uncertainty assessment of health economic models, using the model described in Chapter 5 as a case study. The aim was to parameterize all influential uncertainties and reflect them in the cost-effectiveness probability and risk associated with the adoption decision. The uncertainties applying to the model were identified and added to the probabilistic sensitivity analysis if possible. Parameter distributions were obtained by expert elicitation, and structural uncertainties were either parameterized or explored in scenario analyses 
which were model averaged. The case study highlighted that a truly comprehensive uncertainty assessment could not be achieved, and several subjective judgments and decisions were necessary in the process of the uncertainty assessments, which potentially reduced the comprehensiveness and transparency of the approach. Expert elicitation regarding the value of parameters that were uncertain showed to be a useful tool in parameterizing previously unexplored uncertainties, and in reflecting them in the costeffectiveness results. Guidance regarding the use of applicable methodologies, such as the selection of uncertainties, the use of expert elicitation, the aggregation of elicited and existing data, the use of model averaging, and reporting the results in a comprehensive and transparent manner was missing and perceived as a barrier to the comprehensive uncertainty assessment. The use of existing tools such as TRUST for the assessment of uncertainties (20), and EXPLICIT for the elicitation of expert opinion (21) were perceived as facilitators. The study provided an example of how comprehensive uncertainty assessment can be conducted by utilizing existing tools and available sources of expert knowledge. It also underlined that the requirements for comprehensive uncertainty assessment need better definition by those potentially using it - decision makers in healthcare - and more attention regarding the development of guidance and instructions for the appropriate use of methodologies is needed.

The last chapter (Chapter 7) of this dissertation summarizes the main findings and discusses implications on HTA methodology. Furthermore, implications on clinical and policy decisions making regarding care for PAD patients are outlined. Based on the research conducted, areas that require further research are described. Regarding the field of HTA, these include the handling of missing cost data, the systematic identification and parameterization of uncertainties relating to health economic models and the use of expert elicitation tools in HTA. Regarding the clinical and policy aspects of care for PAD patients, these include the further development of prediction tools for the anticipation of future treatment needs, the use of intensified conservative treatment and the role of nonclinical characteristics in the treatment pathway of PAD patients. 


\section{References}

1. Fowkes FGR, Rudan D, Rudan I, Aboyans V, Denenberg JO, McDermott MM, et al. Comparison of global estimates of prevalence and risk factors for peripheral artery disease in 2000 and 2010: a systematic review and analysis. Lancet. 2013;382(9901):1329-40.

2. Aboyans V, Ricco J-B, Bartelink M-LEL, Björck M, Brodmann M, Cohnert T, et al. 2017 ESC Guidelines on the Diagnosis and Treatment of Peripheral Arterial Diseases, in collaboration with the European Society for Vascular Surgery (ESVS)Document covering atherosclerotic disease of extracranial carotid and vertebral, mesenteric, renal, upper and lower extremity arteriesEndorsed by: the European Stroke Organization (ESO)The Task Force for the Diagnosis and Treatment of Peripheral Arterial Diseases of the European Society of Cardiology (ESC) and of the European Society for Vascular Surgery (ESVS). Eur Heart J. 2017:ehx095-ehx.

3. Breek JC, Hamming JF, De Vries J, Aquarius AE, van Berge Henegouwen DP. Quality of life in patients with intermittent claudication using the World Health Organisation (WHO) questionnaire. Eur J Vasc Endovasc Surg. 2001;21(2):118-22.

4. Aquarius AE, Denollet J, Hamming JF, Breek JC, De Vries J. Impaired health status and invasive treatment in peripheral arterial disease: A prospective 1-year follow-up study. J Vasc Surg. 2005;41(3):436-42.

5. Alberts MJ, Bhatt DL, Mas J-L, Ohman EM, Hirsch AT, Röther J, et al. Three-year follow-up and event rates in the international REduction of Atherothrombosis for Continued Health Registry. European Heart Journal. 2009;30(19):2318-26.

6. Bonaca MP, Bhatt DL, Storey RF, Steg PG, Cohen M, Kuder J, et al. Ticagrelor for Prevention of Ischemic Events After Myocardial Infarction in Patients With Peripheral Artery Disease. Journal of the American College of Cardiology. 2016;67(23):2719-28.

7. Bonaca MP, Scirica BM, Creager MA, Olin J, Bounameaux H, Dellborg M, et al. Vorapaxar in Patients With Peripheral Artery Disease. Circulation. 2013;127(14):1522-9.

8. Anand SS, Bosch J, Eikelboom JW, Connolly SJ, Diaz R, Widimsky P, et al. Rivaroxaban with or without aspirin in patients with stable peripheral or carotid artery disease: an international, randomised, double-blind, placebo-controlled trial. Lancet. 2017.

9. Sabatine MS, Giugliano RP, Keech AC, Honarpour N, Wiviott SD, Murphy SA, et al. Evolocumab and Clinical Outcomes in Patients with Cardiovascular Disease. N Engl J Med. 2017;376(18):1713-22.

10. Robinson J, Farnier M, Krempf M, Bergeron J, Luc G, Averna M, et al. Efficacy and Safety of Alirocumab in Reducing Lipids and Cardiovascular Events. N Engl J Med. 2015;372(16):1489-99.

11. Spreen MI, Martens JM, Knippenberg B, van Dijk LC, M. dVJ-PP, J. AV, et al. Long-Term Followup of the PADI Trial: Percutaneous Transluminal Angioplasty Versus Drug-Eluting Stents for Infrapopliteal Lesions in Critical Limb Ischemia. Journal of the American Heart Association. 2017;6(4):e004877. 
12. Rastan A, Tepe G, Krankenberg H, Zahorsky R, Beschorner U, Noory E, et al. Sirolimus-eluting stents vs. bare-metal stents for treatment of focal lesions in infrapopliteal arteries: a double-blind, multi-centre, randomized clinical trial. European Heart Journal. 2011;32(18):2274-81.

13. Scheinert D, Katsanos K, Zeller T, Koppensteiner R, Commeau P, Bosiers M, et al. A Prospective Randomized Multicenter Comparison of Balloon Angioplasty and Infrapopliteal Stenting With the Sirolimus-Eluting Stent in Patients With Ischemic Peripheral Arterial Disease: 1-Year Results From the ACHILLES Trial. Journal of the American College of Cardiology. 2012;60(22):2290-5.

14. Siablis D, Kitrou PM, Spiliopoulos S, Katsanos K, Karnabatidis D. Paclitaxel-Coated Balloon Angioplasty Versus Drug-Eluting Stenting for the Treatment of Infrapopliteal Long-Segment Arterial Occlusive Disease: The IDEAS Randomized Controlled Trial. JACC: Cardiovascular Interventions. 2014;7(9):1048-56.

15. Bosiers $M$, Scheinert D, Peeters $P$, Torsello $G$, Zeller $T$, Deloose $K$, et al. Randomized comparison of everolimus-eluting versus bare-metal stents in patients with critical limb ischemia and infrapopliteal arterial occlusive disease. Journal of Vascular Surgery. 2012;55(2):390-8.

16. Davis T, Ramaiah V, Niazi K, Martin Gissler H, Crabtree T. Safety and effectiveness of the Phoenix Atherectomy System in lower extremity arteries: Early and midterm outcomes from the prospective multicenter EASE study. Vascular. 2017;25(6):563-75.

17. Schwindt AG, Bennett JG, Crowder WH, Dohad S, Janzer SF, George JC, et al. Lower Extremity Revascularization Using Optical Coherence Tomography-Guided Directional Atherectomy: Final Results of the EValuatlon of the PantheriS OptIcal COherence Tomography ImagiNg Atherectomy System for Use in the Peripheral Vasculature (VISION) Study. Journal of Endovascular Therapy. 2017;24(3):355-66.

18. Meijer WT, Cost B, Bernsen RMD, Hoes AW. Incidence and management of intermittent claudication in primary care in The Netherlands. Scandinavian Journal of Primary Health Care. 2002;20(1):33-4.

19. Wilkins E, Wilson L, Wickramasinghe K, Bhatnagar P, Leal J, Luengo-Fernandez R, et al. European Cardiovascular Disease Statistics 2017. European Heart Network; 2017.

20. Grimm SE, Pouwels X, Ramaekers BLT, Wijnen B, Knies S, Grutters J, et al. Development and Validation of the TRansparent Uncertainty ASsessmenT (TRUST) Tool for Assessing Uncertainties in Health Economic Decision Models. PharmacoEconomics. 2020;38(2):205-16.

21. Grigore B, Peters J, Hyde C, Stein K. EXPLICIT: a feasibility study of remote expert elicitation in health technology assessment. BMC Medical Informatics and Decision Making. 2017;17(1):131.

22. Briggs A, Sculpher M. An Introduction to Markov Modelling for Economic Evaluation. PharmacoEconomics. 1998;13(4):397-409. 